\title{
Successful Prophylaxis of Experimental Streptococcal Endocarditis with Single-Dose Amoxicillin Administered after Bacterial Challenge
}

\author{
P. Berney and P. Francioli
}

From the Division of Infectious Diseases, Department of Internal
Medicine, Centre Hospitalier Universitaire Vaudois, Lausanne, Switzerland

\begin{abstract}
Rats with catheter-induced aortic vegetations were challenged intravenously with various inoculum sizes of tolerant Streptococcus sanguis or Streptococcus faecalis. Single-dose amoxicillin (40 $\mathrm{mg} / \mathrm{kg}$ ) was given intravenously either $30 \mathrm{~min}$ before or $30-240 \mathrm{~min}$ after bacterial challenge. Prophylaxis of endocarditis against both strains was successful when the inocula used for challenge were in the range of the minimum inoculum producing bacterial endocarditis in $90 \%$ of control animals $\left(\mathrm{ID}_{90}\right)$ but was less effective or failed with larger inocula or when amoxicilin administration was delayed up to $\mathbf{2 4 0}$ min after bacterial challenge with $S$. sanguis. In a group of rats profoundly depleted of neutrophils by a rabbit anti-rat neutrophil serum given $\mathbf{3 0}$ min after challenge with $S$. faecalis at $\mathbf{I D}_{90}$, single-dose amoxicillin administered simultaneously with the antiserum was protective, indicating that neutrophils were not required for successful endocarditis prophylaxis.
\end{abstract}

Prevention of bacterial endocarditis by prophylactic antibiotics is recommended in patients at risk who are undergoing dental or medical procedures that may produce bacteremia [1]. The recommendation advocates antibiotic administration before the procedure, followed by one or more subsequent doses. The rationale was to have bactericidal antibiotic levels at the time bacteria would reach the circulation [2]. However, several experimental studies have shown that prophylaxis could be achieved in the absence of bacterial killing $[3,4]$ possibly by inhibiting the adherence of bacteria to the damaged cardiac valves, reinforcing the recommendations of antibiotic administration before the procedure [5-7].

However, recent observations have challenged the role of inhibition of bacterial adherence as a likely mechanism of successful prophylaxis in the absence of bacterial killing [8]. Indeed, these observations suggest that prophylactic antibiotics operate by inhibiting the growth of bacteria that adhere to vegetations during the bacteremic phase, allowing as-yet-undefined host defense mechanisms to progressively clear these bacteria from the valves.

We reasoned that if inhibition of growth, not of adherence, was a likely mechanism by which antibiotics prevented endocarditis, antibiotics administered after the bacteremic phase might also be successful. Thus, we attempted to determine

Received 27 December 1988; revised 12 June 1989

Published in part as abstract 279 in the Program and Abstracts of the 26th Interscience Conference on Antimicrobial Agents and Chemotherapy.

Supported by grant 3-864-0.86 from the Swiss National Foundation for Scientific Research.

Reprints and correspondence: Dr. P. Francioli, Division of Infectious Diseases, Department of Internal Medicine, Centre Hospitalier Universitaire Vaudois, 1011 Lausanne, Switzerland.

The Journal of Infectious Diseases 1990;161:281-285

(C) 1990 by The University of Chicago. All rights reserved.

0022-1899/90/6102-0020\$01.00 the efficacy of antibiotics administered after the bacteremic phase in preventing endocarditis and to investigate the role of neutrophils in the successful antibiotic prevention of endocarditis.

\section{Materials and Methods}

Microorganisms. Two strains of streptococci, one Streptococcus sanguis and one Streptococcus faecalis, isolated from patients with bacterial endocarditis were used.

The minimum inhibitory concentrations (MIC) of amoxicillin were determined by the broth macrodilution technique using an inoculum of $10^{5} \mathrm{cfu} / \mathrm{ml}$ of each strain from an overnight culture. The minimum bactericidal concentrations (MBC) were determined by subculturing on blood-agar plates supplemented with penicillinase (Difco, Detroit), $100 \mu \mathrm{l}$ from each dilution of antibiotic showing no turbidity after $18 \mathrm{~h}$ of incubation.

Killing curves were determined in Mueller-Hinton broth (GIBCO, Paisley, Scotland) with an inoculum of $10^{6} \mathrm{cfu} / \mathrm{ml}$ of each strain from an overnight culture using concentrations of amoxicillin of 10 $\mu \mathrm{g} / \mathrm{ml}$ (corresponding to 10 times the MIC) and $100 \mu \mathrm{g} / \mathrm{ml}$ (corresponding to a concentration above the maximum peak serum value obtained immediately after an intravenous [iv] injection of $40 \mathrm{mg} / \mathrm{kg}$ of amoxicillin).

Amoxicillin serum levels and serum inhibitory and bactericidal titers. Serum levels of amoxicillin were determined 2, 30, 60, 120, and $240 \mathrm{~min}$ after injection of $40 \mathrm{mg} / \mathrm{kg}$ iv amoxicillin in catheterized rats by a standard agar diffusion technique. Bacillus subtilis was used as the test organism and normal rat serum was used as the diluent [9].

The serum inhibitory and bactericidal titers against $S$. sanguis and $S$. faecalis $30 \mathrm{~min}$ and 2,4 , and $6 \mathrm{~h}$ after iv administration of $40 \mathrm{mg}$ of amoxicillin $/ \mathrm{kg}$ of body weight were determined in three rats by standard methods [9] with an inoculum of $10^{6} S$. sanguis and $S$. faecalis. Subcultures were performed on penicillinase-containing blood agar (Bactopenase, $5 \times 10^{6} \mathrm{IU} / 1$; Difco). The serum inhibitory titer was the highest dilution of serum inhibiting visible bacterial growth, and the serum bactericidal titer was the highest dilution 
of serum providing $99.9 \%$ killing of the original inoculum after incubation for $18 \mathrm{~h}$.

Animal model-production of endocarditis. Sterile aortic vegetations were produced in female Wistar rats $(180-200 \mathrm{~g})$ by a method previously described [4]. In brief, a polyethylene catheter was placed through the right carotid artery across the aortic valve and secured with a silk ligature.

Twenty-four hours after catheterization, rats were injected in the tail vein with $0.5 \mathrm{ml}$ of various amounts of bacteria from an overnight culture (bacterial challenge). Inoculum sizes were $10^{6}, 10^{7}$, $10^{8} \mathrm{cfu}$ in the experiments with $S$. sanguis and $10^{4}$ or $10^{5} \mathrm{cfu}$ in the experiments with $S$. faecalis. The lowest inoculum of each strain corresponds to the minimum inoculum producing bacterial endocarditis in $90 \%$ of control animals $\left(\mathrm{ID}_{90}\right)$. In all experiments, animals were killed 3 days after bacterial challenge. Aortic vegetations were excised, homogenized in $1 \mathrm{ml}$ of saline, serially diluted, and plated. Plates were counted $24-48 \mathrm{~h}$ after incubation at $37^{\circ} \mathrm{C}$.

Effect of single-dose amoxicillin administered before or after bacterial challenge. For each inoculum of the two strains, groups of rats of the same experiment were given a single dose of iv amoxicillin $(40 \mathrm{mg} / \mathrm{kg})$ administered either $30 \mathrm{~min}$ before or at various times after bacterial challenge. Control animals were given iv saline. In all experiments, controls and treated rats were handled concurrently.

Production of a rabbit anti-nat neutrophil serum (ANS). Rat neutrophils were harvested from peritoneal exudate $4 \mathrm{~h}$ after intraperitoneal (ip) injection of $5 \mathrm{ml}$ of a solution of $3 \%$ thioglycolate. The cells were briefly suspended in distilled water to hemolyze residual red cells, washed, and resuspended in Hanks' balanced salt solution. The final cell suspension consisted of $>98 \%$ neutrophils $[10,11]$. Ten New Zealand rabbits $(2.5 \mathrm{~kg})$ were injected iv with $7 \times 10^{7}$ rat neutrophils at days 1,8 , and 14 . The serum was collected at day 28 and again 10 days after a fourth injection of rat neutrophils. The samples of serum were pooled, decomplemented by heating at $56^{\circ} \mathrm{C}$ for $30 \mathrm{~min}$, absorbed against rats erythrocytes for $30 \mathrm{~min}$ (in order to avoid hemolysis when injected in rats), and stored in aliquots at $-80^{\circ} \mathrm{C}$. Control serum (CS) was collected from nonimmunized rabbits and processed in the same way.

ANS administration and neutrophil counts. ANS or CS was injected in catheterized rats $30 \mathrm{~min}$ after iv bacterial challenge with $10^{4} \mathrm{cfu}$ of $S$. faecalis and the neutrophil counts determined at 5 and $30 \mathrm{~min}$ and $3,6,24,48$, and $72 \mathrm{~h}$ thereafter. ANS or CS was injected simultaneously iv and ip in a volume of $1 \mathrm{ml}$ at each site of administration. Blood cells counts were performed by an automatic analyzer (Sysmex CC-800; TOA Medical Electronics, Japan).

Effect of neutrophil depletion on the efficacy of amoxicillin administered after bacterial challenge. Twenty-four hours after catheterization, animals were challenged with $10^{4} \mathrm{cfu}$ of $\mathrm{S}$. faecalis $\left(\mathrm{ID}_{90}\right)$, and amoxicillin or saline was administered $30 \mathrm{~min}$ later (i.e., at a time when circulating bacteria could no longer be detected as previously shown [5]).

Rats given amoxicillin were divided into three groups and received amoxicillin alone, amoxicillin plus ANS, or amoxicillin plus CS. ANS and CS were injected at the same time as the antibiotic and administered both iv $(1 \mathrm{ml})$ and ip $(1 \mathrm{ml})$ to obtain a rapid and prolonged neutropenia. Control rats received CS.

Effect of neutrophil depletion on bacteremia. To detect if release of bacteria in the circulation from extravascular foci was expedited by neutropenia in animals given ANS and amoxicillin, blood $(0.5 \mathrm{ml})$ was collected by jugular puncture $90 \mathrm{~min}$ after bacterial challenge and was plated onto penicillinase-supplemented blood-agar medium. The plates were incubated and examined after $48 \mathrm{~h}$.

Statistical evaluation. The $\chi^{2}$ test with Yates's correction was used for statistical comparisons.

\section{Results}

Minimum inhibitory and bactericidal concentrations. The MIC and MBC of amoxicillin were 0.032 and $128 \mu \mathrm{g} / \mathrm{ml}$, respectively, for $S$. sanguis and 1 and $128 \mu \mathrm{g} / \mathrm{ml}$ for $S$. faecalis. These two strains were defined as tolerant to amoxicillin, with an MBC-to-MIC ratio well above 32.

Time-kill curve studies. No significant killing occurred during the first $6 \mathrm{~h}$ of exposure to amoxicillin for the two strains, with two different dosages of amoxicillin (figure 1). There was no difference between 10 and $100 \mu \mathrm{g} / \mathrm{ml}$.

Serum antibiotic levels in rats and serum inhibitory and bactericidal titers against $S$. sanguis and $S$. faecalis. Serum levels of amoxicillin (mean $\pm S D$ for three rats at each time interval) after iv injection of $40 \mathrm{mg} / \mathrm{kg}$ amoxicillin were 188 $\pm 12.5 \mu \mathrm{g} / \mathrm{ml}$ at $2 \mathrm{~min}, 40 \pm 5.8 \mu \mathrm{g} / \mathrm{ml}$ at $30 \mathrm{~min}, 12.7 \pm$ $2.9 \mu \mathrm{g} / \mathrm{ml}$ at $60 \mathrm{~min}, 1.9 \pm 0.7 \mu \mathrm{g} / \mathrm{ml}$ at $120 \mathrm{~min}$, and 0.6 $\pm 0.1 \mu \mathrm{g} / \mathrm{ml}$ at $240 \mathrm{~min}$.

For $S$. sanguis, the mean serum inhibitory titer $30 \mathrm{~min}, 2 \mathrm{~h}$, and $4 \mathrm{~h}$ after iv injection of amoxicillin was $1 / 32$; after $6 \mathrm{~h}$ it was $1 / 8$. For $S$. faecalis, the mean serum inhibitory titer $30 \mathrm{~min}$ after injection of amoxicillin was $1 / 4$. No serum inhibitory activity was detectable at 2,4 , or $6 \mathrm{~h}$. For both strains, no serum bactericidal activity could be detected at any time.

Effect of single-dose amoxicillin administered before or after bacterial challenge with $S$. sanguis. As previously observed [12], amoxicillin given $30 \mathrm{~min}$ before bacterial challenge was successful in preventing $S$. sanguis endocarditis, provided that the infectious dose was in the range of the $\mathrm{ID}_{90}\left(10^{6}-10^{7}\right.$

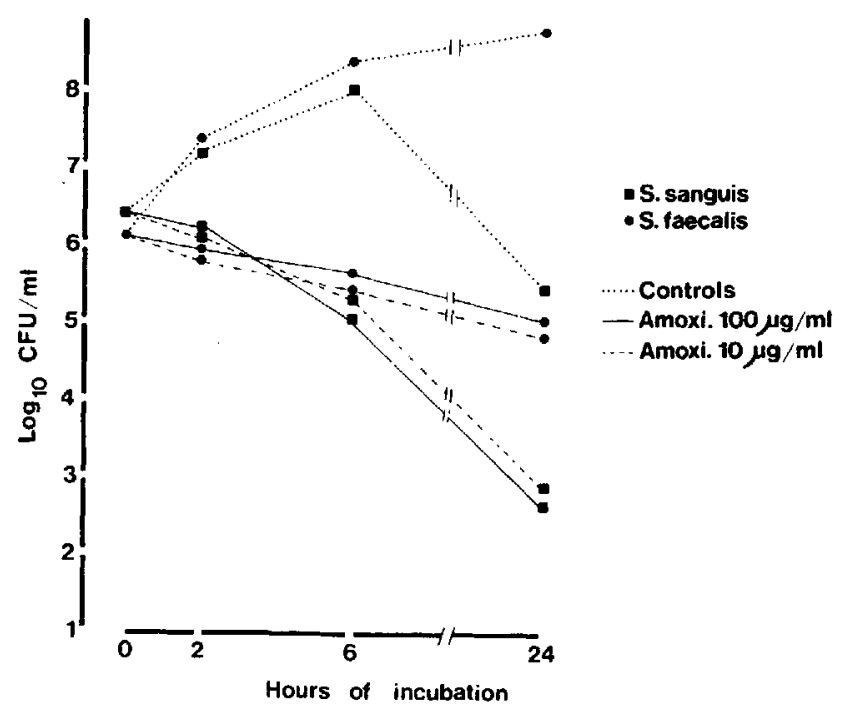

Figure 1. Rates of in vitro killing of Streptococcus sanguis and Streptococcus faecalis by 10 and $100 \mu \mathrm{g} / \mathrm{ml}$ of amoxicillin (Amoxi). 
cfu) (figure 2). Amoxicillin failed with a higher inoculum size (10 $\left.{ }^{8} \mathrm{cfu}\right)$.

When amoxicillin was administered $30 \mathrm{~min}$ after bacterial challenge (i.e., when circulating bacteria were no longer detectable in the blood) or $120 \mathrm{~min}$ after challenge, excellent protection was also observed with inocula in the range of the $\mathrm{ID}_{90}$ but vanished with higher inocula. When amoxicillin was administered $240 \mathrm{~min}$ after challenge, no protection was observed.

Effect of single dose amoxicillin administered before and after bacterial challenge with $S$. faecalis. Results obtained were similar to those with $S$. sanguis (figure 3). Excellent protection was achieved with amoxicillin administered either 30 min before or 30-120 min after bacterial challenge with inoculum sizes not higher than the $\mathrm{ID}_{90}$. With an inoculum 10 times the $\mathrm{ID}_{90}$, the protective effect decreased substantially when amoxicillin was given either $30 \mathrm{~min}$ before or $120 \mathrm{~min}$ after bacterial challenge.

Effect of ANS on neutrophil counts of infected rats. Administration of ANS resulted in a rapid ( $<5 \mathrm{~min}$ ) and profound $(>99 \%)$ decrease in the number of circulating neutrophils lasting over $6 \mathrm{~h}$ (figure 4), which contrasted with an increased neutrophil count observed in rats given CS. The few residual neutrophils detected during the period of neutropenia showed marked morphologic alterations, suggesting possible functional impairment. Neutrophil counts returned to baseline values after 48-72 h. Lymphocyte and monocyte counts were not affected, but circulating platelet numbers were decreased about fivefold in parallel to neutrophil counts.

Blood cultures performed on penicillinase-supplemented agar plates $1 \mathrm{~h}$ after ANS injection in rats (i.e., $90 \mathrm{~min}$ after
S. faecalis

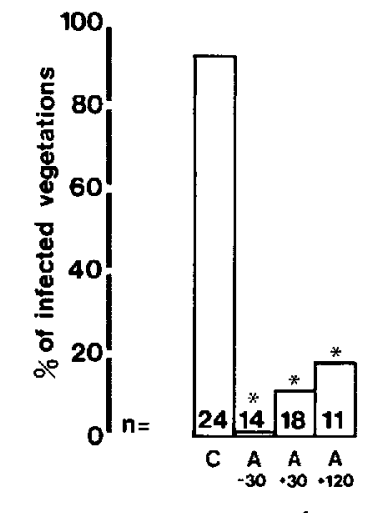

Inoculum size:

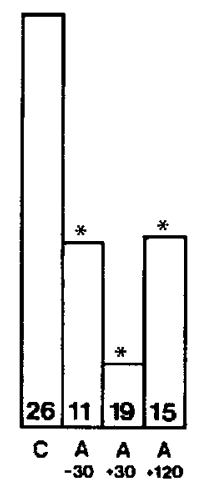

$10^{5}$

Figure 3. Incidence of endocarditis in control rats $(\mathrm{C})$ and in rats given amoxicillin $30 \mathrm{~min}$ before $(\mathrm{A}-30)$ or $30-120 \mathrm{~min}$ after $(A+30-A+120)$ bacterial challenge with various inocula of $S$. faecalis. See figure 2 legend for details.

bacterial challenge) were sterile, providing evidence for the absence of secondary bacteremia during the neutropenic episodes.

Effect of single-dose amoxicillin administered 30 min after bacterial challenge with $S$. faecalis in neutropenic rats. Successful amoxicillin prophylaxis was achieved in rats with ANSinduced neutropenia as well as in rats with normal neutrophil counts. This indicated that neutrophils were not required for the successful protection conferred by amoxicillin given after S. faecalis challenge (figure 5).
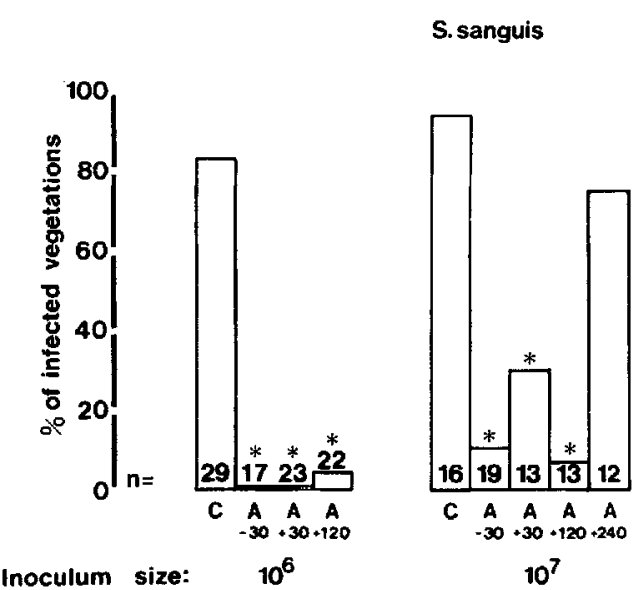

Figure 2. Incidence of endocarditis in control rats $(C)$ and in rats given amoxicillin $30 \mathrm{~min}$ before $(\mathrm{A}-30)$ or 30-240 $\mathrm{min}$ after $(\mathrm{A}+30-\mathrm{A}+240)$ bacterial challenge with various inocula of $S$. sanguis. $P$ values were calculated by $\chi^{2}$ analysis with Yates's correction; asterisk indicates $P<.05$ compared with controls. There were no significant statistical differences between $A-30, A+30$, and $\mathrm{A}+120$.
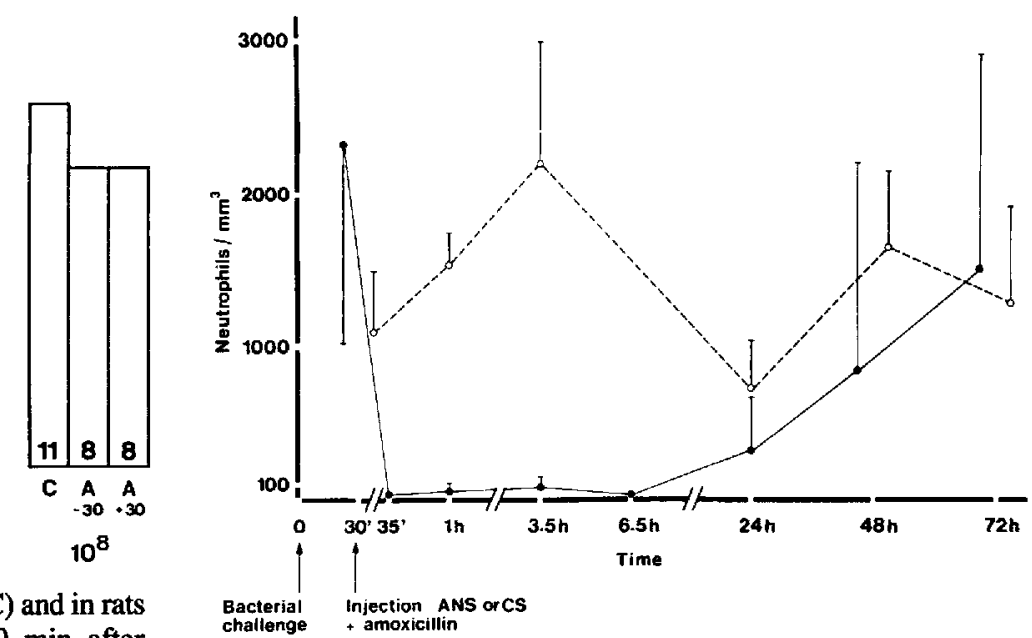

Figure 4. Effect of anti-rat neutrophil serum (ANS) and control serum (CS) on neutrophil counts of catheterized control $(O)$ and ANS-treated (O) rats inoculated with $10^{4}$ cfu of $S$. faecalis. Each point represents mean neutrophils $\pm S D$ (vertical lines) at time after bacterial challenge. 


\section{S.faecalis}

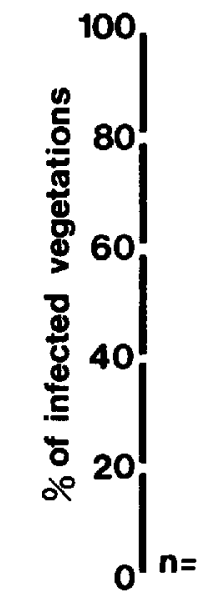

Inoculum size:

Figure 5. Incidence of endocarditis in rats challenged with $10^{4}$ cfu of $S$. faecalis and given saline (C), amoxicillin alone (A), amoxicillin plus anti-rat neutrophil serum (A+ANS), or amoxicillin plus control serum $(\mathrm{A}+\mathrm{CS})$. Asterisk indicates $P<.05$ compared with controls.

\section{Discussion}

Several experimental studies have shown that single doses of amoxicillin or other antibiotics administered before bacterial challenge successfully prevented endocarditis in the absence of bacterial killing, provided that the inoculum size was in the range of the $\mathrm{ID}_{90}[3,4,8]$. Under these circumstances, inhibition of bacterial adherence to the vegetations has been proposed as the main mechanism of action of antibiotics responsible for successful prevention of endocarditis.

Previous in vitro experiments indicated a decreased ability of bacteria treated with antibiotics to adhere to platelet-fibrin matrices mimicking endocardial vegetations, but experiments with animals injected with antibiotic-pretreated bacteria gave contradictory results [5-7]. Thus the biologic importance of inhibition of adherence by antibiotics was uncertain.

In a recent study, Moreillon et al. [8] showed that the protective effect of amoxicillin given before bacterial challenge was lost if amoxicillin was inactivated by penicillinase injected at the end of bacteremia, demonstrating that inhibition of adherence was not a likely mechanism of successful prophylaxis in these experiments. Moreover, these observations suggested that prolonged inhibition of bacterial growth on the surface of the vegetations was required for successful prevention of endocarditis.

In the present study, we observed that amoxicillin given 30 or $120 \mathrm{~min}$ after bacterial challenge was as effective as the antibiotic given before challenge in preventing $S$. sanguis and $S$. faecalis endocarditis. Thus, the observation that amoxicil- lin was effective if administered when the bacteria had already adhered to the vegetations and could no longer be recovered from the blood [5] strengthens the evidence that protection was not conferred by inhibition of adherence of the bacteria to the damaged valves. This confirms early experiments performed by Durack and Petersdorf [2], who reported protection in rabbits injected with streptococci and given high doses of procaine penicillin $30 \mathrm{~min}$ after bacterial challenge.

Detachment of the adherent bacteria from the vegetations through structural modification of the bacterial wall during exposure to circulating amoxicillin has been proposed as a possible mechanism for successful prophylaxis $[7,8]$. In our experiments, however, blood cultures onto penicillinasecontaining media performed after amoxicillin administration were sterile. Moreover, this hypothesis is not supported by our previous in vitro experiments in which bacteria attached to platelet-fibrin matrices did not show increased detachment when exposed to and washed with bacteriostatic concentrations of amoxicillin for $4 \mathrm{~h}$, a period simulating the time of exposure to amoxicillin in vivo [8]. Therefore, detachment of adherent bacteria appears to be an unlikely mechanism by which bacteria are released from the vegetations. However, this cannot be totally ruled out, because of the methodologic difficulty of showing a phenomenon that implicates only a very small number of bacteria.

Bacterial killing has been considered as a potential mechanism of action of prophylactic antibiotic. However, this mode of action does not seem to account for the present results, because the streptococcal strains used were tolerant to amoxicillin, particularly $S$. faecalis, which is notoriously resistant to the bactericidal actions of $\beta$-lactams.

Moreover, no serum bactericidal activity was detected in vivo at any time. Killing curves performed in vitro with amoxicillin concentrations as high as $100 \mu \mathrm{g} / \mathrm{ml}$ showed no significant killing during the first $2 \mathrm{~h}$ of exposure and a reduction of $<1 \log$ after $6 \mathrm{~h}$ (figure 1). Therefore, these observations provide further evidence that mechanisms other than bacterial killing are involved in the successful antibiotic prophylaxis of endocarditis.

Previous experiments have shown that after the initial attachment of bacteria that follows the challenge, the bacterial counts at the surface of the vegetation decreased progressively during the first $2 \mathrm{~h}$, even in the absence of prophylactic antibiotics [8]. From $2 \mathrm{~h}$ on, if residual organisms were still present, bacterial counts increased again because of resumed multiplication. In animals given amoxicillin $30 \mathrm{~min}$ before bacterial challenge and injected with increasing inoculum sizes up to the $\mathrm{ID}_{90}$, this natural decrease in bacterial counts was prolonged beyond $2 \mathrm{~h}$ by the bacteriostatic action of amoxicillin, so that the bacteria were cleared from the vegetations and endocarditis could not develop later.

In the present experiments, successful prophylaxis was also observed in rats given amoxicillin up to $2 \mathrm{~h}$ after bacterial challenge. This effect however was limited to animals chal- 
lenged with bacterial inocula not higher than the $\mathrm{ID}_{90}$ for both strains; also it vanished when amoxicillin administration was delayed up to $4 \mathrm{~h}$ after challenge with $S$. sanguis (figure 2). Prior experiments have shown that in control animals, bacterial growth on the vegetations has begun at $4 \mathrm{~h}$ and counts are 10-fold higher than counts at $30 \mathrm{~min}$ [8]. In fact, the counts at $4 \mathrm{~h}$ after injection of the $\mathrm{ID}_{90}$ were similar to those obtained at $30 \mathrm{~min}$ in animals injected with 10 times the $\mathrm{ID}_{90}$. In the latter animals a higher rate of prophylaxis failure was observed compared with that in animals challenged with the $\mathrm{ID}_{90}$. This might explain the present results in which single-dose amoxicillin administered $4 \mathrm{~h}$ after bacterial challenge with $S$. sanguis at the $\mathrm{ID}_{90}$ failed to prevent endocarditis. Successful prophylaxis could possibly be restored by using multiple doses of amoxicillin as demonstrated in animals challenged with inocula $10-1000$ times the $\mathrm{ID}_{90}$ [13].

Since the clearance of bacteria from the vegetations appeared to be a likely mechanism operating in endocarditis prophylaxis, we further investigated whether the neutrophils would contribute to this effect and therefore be implicated in the success of amoxicillin in preventing endocarditis. We found that a profound and rapid neutropenia (figure 4) induced after the end of the bacteremia did not decrease the prophylactic efficacy of amoxicillin (figure 5). These experiments showed that the granulocytes were unlikely to play an important role in the clearance of bacteria from the vegetations, suggesting that either mere mechanical detachment of bacteria (but not detectable by blood culture) or possibly a platelet-mediated bactericidal activity [14] could be responsible for successful amoxicillin prophylaxis in the absence of bacterial killing.

In conclusion, the present study indicates that single-dose amoxicillin given after bacterial challenge can successfully prevent experimental endocarditis due to tolerant streptococcal strains, provided that the inoculum size is not greater than the $\mathrm{ID}_{x}$ and that antibiotic administration occurs within $2 \mathrm{~h}$ after bacterial challenge. Neutrophils do not appear to be a contributing factor to successful prophylaxis of experimental endocarditis.

\section{Acknowledgment}

We thank Dr. M. P. Glauser for comments, Marlies Knaup and Marlyse Giddey for technical assistance, and Marie-Agnès Blanc for typing.

\section{References}

1. Shulman ST, Amren DP, Bisno AL, Dajani AS, Durack DT, Gerber MA, Kaplan EL, Millard HD, Sanders WE, Schwartz RH, Watanakunakorn C. Prevention of bacterial endocarditis: a statement for health professionals by the Committee on Rheumatic Fever and Infective Endocarditis of the Council on Cardiovascular Disease in the Young. Circulation 1984;70:1123A-1127A

2. Durack DT, Petersdorf RG. Chemotherapy of experimental streptococcal endocarditis. I. Comparison of commonly recommended prophylactic regimens. J Clin Invest 1973;52:592-598

3. Glauser MP, Francioli P. Successful prophylaxis against experimental streptococcal endocarditis with bacteriostatic antibiotics. J Infect Dis 1982;146:806-810

4. Glauser MP, Bernard JP, Moreillon P, Francioli P. Successful singledose amoxicillin prophylaxis against experimental streptococcal endocarditis: evidence for two mechanisms of protection. J Infect Dis 1983;147:568-575

5. Bernard JP, Francioli P, Glauser MP. Vancomycin prophylaxis of experimental Streptococcus sanguis endocarditis. Inhibition of bacterial adherence rather than bacterial killing. J Clin Invest 1981;68:1113-1116

6. Scheld WM, Zak O, Vosbeck K, Sande MA. Bacterial adhesion in the pathogenesis of infective endocarditis: effect of subinhibitory antibiotic concentrations on streptococcal adhesion in vitro and the development of endocarditis in rabbits. J Clin Invest 1981;68:1381-1384

7. Lowy FD, Chang DS, Neuhaus EG, Horne DS, Tomasz A, Steigbigel NH. Effect of penicillin on the adherence of Streptococcus sanguis in vitro and in the rabbit model of endocarditis. J Clin Invest 1983; 71:668-675

8. Moreillon P, Francioli P, Overholser D, Meylan P, Glauser MP. Mechanisms of successful amoxicillin prophylaxis of experimental endocarditis due to Streptococcus intermedius. J Infect Dis 1986;154:801-807

9. Anhalt JP. Assays for antimicrobial agents in body fluid. In: Lennette EH, Balows A, Hausler WJ Jr, Shadomy HJ, eds. Manual of clinical microbiology. 4th ed. Washington, DC: American Society for Microbiology, 1985:1109

10. Stanley RR, Gary NG, David AH, Alan KP. Animal model of neutropenia suitable for the study of dual-phagocyte system. Infect Immun 1979;25:299-303

11. Sandler H, Högstorp H, Lundberg C, Gerdin B. Antiserum-induced neutropenia in the rat: characterization of a rabbit anti-rat neutrophil serum. Br J Exp Pathol 1987;68:71-80

12. Francioli P, Moreillon $P$, Glauser MP. Comparison of single doses of amoxicillin or of amoxicillin-gentamicin for the prevention of endocarditis caused by Streptococcus faecalis and by viridans streptococci. J Infect Dis 1985;152:83-89

13. Malinverni R, Francioli P, Glauser MP. Comparison of single and multiple doses of prophylactic antibiotics in experimental streptococcal endocarditis. Circulation 1987;76:376-382

14. Dankert J, Hess J, Durack D. Pathogenesis of viridans streptococci from vegetations [abstract 278]. In: Program and abstracts of the 26th Interscience Conference on Antimicrobial Agents and Chemotherapy (New Orleans). Washington, DC: American Society for Microbiology, 1986 